\title{
Effects of Allopurinol on Tissue Oxygen Tension of the Ischemic Myocardium
}

\author{
Akira Furuse, M.D., Hiroshi Inoue, M.D., Akira Mizuno, \\ M.D., and Masahiro SAigusa, M.D.
}

\section{SUMmary}

The effects of allopurinol on the myocardial oxygen metabolism were studied in dogs with acute coronary artery occlusion. Upon occlusion of the contributory branch of the coronary artery, myocardial $\mathrm{pO}_{2}$, as measured with an improved polarographic technique, decreased to various lower values depending on the site of the electrode inserted. In the slightly ischemic myocardium, where myocardial $\mathrm{pO}_{2}$ decreased less than $50 \%$ of the control by the coronary occlusion, administration of allopurinol brought about a further diminution in myocardial $\mathrm{pO}_{2}$. In the severely ischemic myocardium, where myocardial $\mathrm{pO}_{2}$ decreased more than $50 \%$ of the control upon the coronary occlusion, no significant change was observed following allopurinol infusion. Theoretical beneficial effects of allopurinol on the ischemic myocardium by preserving functional purine bases might be offset by the aggravation of the negative oxygen balance in the ischemic but still viable myocardium following administration of allopurinol.

\section{Additional Indexing Words :}

Xanthine oxidase inhibitor Polarography Myocardial infarction Chemical revascularization Coronary steal phenomenon Functional purine base

12 ECENTLY the concept of physiologic support has been introduced for K the treatment of acute myocardial infarction. This mode of therapy aims to prescrve myocardial integrity during myocardial hypoxia using various pharmacologic agents. One of the most promising of this group of agent is sodium allopurinol. This compound, synthesized by Elion, ${ }^{1)}$ was introduced into medical practice initially for the treatment of hyperuricemia. More recently it was reported that this drug was effective in the treatment of various types of experimental shock. ${ }^{2-4)}$ The use of this drug as an effective agent in the preservation of the organ to be transplanted has been investigated..$^{5}$

Studies with this agent in experimental myocardial infarction have been

From the Department of Thoracic Surgery, University of Tokyo, 7-3-1 Hongo, Bunkyo-ku, Tokyo 113.

Received for publication May 2, 1975. 
carried out by DeWall and his associates. ${ }^{6}$ In animals with acute myocardial infarction, allopurinol caused an increase in myocardial contractility and cardiac output, reversed or prevented electrocardiographic ST changes of ischemic origin, and exhibited prolonged antiarrhythmic effects. ${ }^{6)}$

Since the agent is a xanthine oxidase inhibitor, it is reasonable to postulate that prevention of the final breakdown of nucleosides and purine bases to the irreversible product of uric acid would allow the accumulation and reutilization of such compound in hypoxia. Some of these compounds are not only intermediates of resynthesis of high energy phosphate substance but also potent dilators of coronary vessels. It is suggested by DeWall and associates that the agent opens up previously nonfunctioning intramural channels or collaterals, or prevents the coronary vasospasm as described by some investigators, ") resulting in chemical revascularization of the myocardium.

The major factor responsible for heart failure following acute myocardial infarction is the relative size of the infarcted or ischemic area of the myocardium which is incapable of significant cardiac work. The total area of ischemia can be divided into 2 zones: One is irreversibly ischemic and will become an infarct despite therapy of any kind; the other is a periinfarction zone, the ultimate viability of which can, perhaps, be influenced by therapy. The viability and function of the periinfarction zone is probably determined by the balance between oxygen consumption and oxygen supply in that area. Since myocardial $\mathrm{pO}_{2}$ as determined either by mass spectrometry or polarography is a measure of myocardial oxygen balance, ${ }^{81,9)}$ interventions which increase myocardial $\mathrm{pO}_{2}$ will theoretically help to prevent necrosis in the periinfarction area, whereas interventions which diminish myocardial $\mathrm{pO}_{2}$ are probably detrimental.

In the previous study which included direct measurement of gas tensions in myocardial tissue by means of a mass spectrometer, the author documented the deleterious effects of isoproterenol and glucagon and the beneficial effect of 1-norepinephrine on myocardial metabolism in animals with coronary artery stenosis. ${ }^{10)}$

In the present investigation, a polarographic technique was used to study the effects of allopurinol on the myocardial oxygen metabolism in animals with acute coronary occlusion.

\section{Materials and Methods}

Twenty-five adult mongrel dogs were anesthetized with $30 \mathrm{mg} / \mathrm{Kg}$ of pentobarbital and ventilated through an endotracheal tube using room air by means of an Aika respirator. The left pleural cavity was entered through the fifth inter- 
costal space. The pericardium was opened widely. Partial pressure of oxygen in the myocardial tissue was continuously measured by an IBC* polarographic oxygen analyzer, ${ }^{11 \prime}$ and recorded on a multichannel recorder. The tip of the electrode for the myocardium was made of gold and coated with Hydron. One or 2 electrodes were inserted into the anterior wall of the left ventricle supplied by the second or third diagonal branch of the left coronary artery. A reference silver-silver chloride electrode was placed subcutaneously in the thoracic wall. Blood pressure was continuously monitored through a polyethylene catheter intrcduced in the femoral artery. Blood flow in the circumflex coronary artery was measured by an electromagnetic flowmeter** in selected animals.

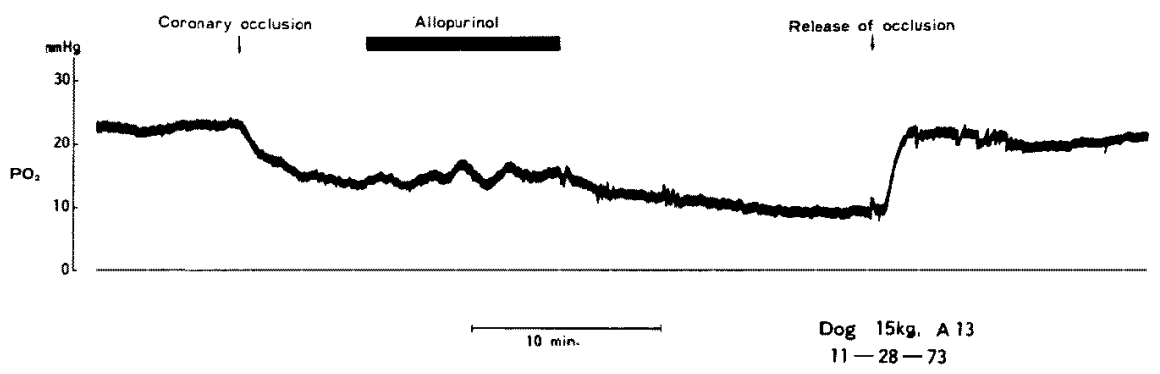

Fig. 1. Change in myocardial $\mathrm{pO}_{2}$ in an experiment.

Following occlusion of the second diagonal branch of the left coronary artery, myocardial $\mathrm{pO}_{2}$ decreased from 23 to $14 \mathrm{mmHg}$. Ten minutes following allopurinol infusion, myocardial $\mathrm{pO}_{2}$ further decreased to $11 \mathrm{mmHg}$. Upon release of the coronary occluder, myocardial $\mathrm{pO}_{2}$ promptly increased to $20 \mathrm{mmHg}$.

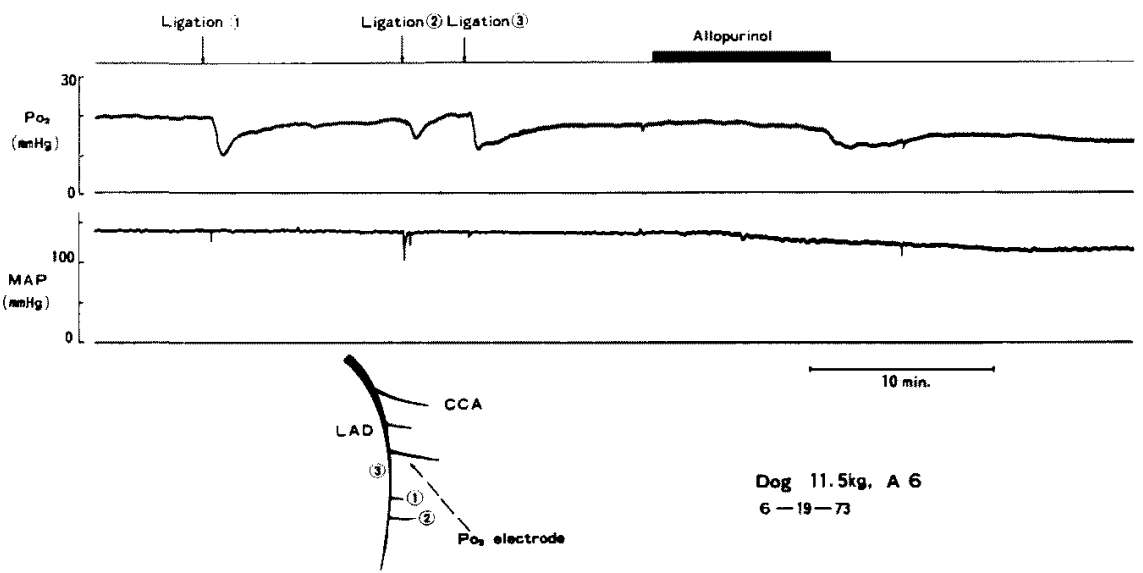

Fig. 2. Changes in myocardial $\mathrm{pO}_{2}$ and mean systemic arterial pressure in an experiment.

Because of prompt return of myocardial $\mathrm{pO}_{2}$ value after occlusion of the third and fourth diagonal branches (ligations 1 and 2), the anterior descending branch was occluded (ligation 3) in order to obtain a stable preparation of myocardial ischemia. Administration of allopurinol brought about decreases both in myocardial $\mathrm{pO}_{2}$ and mean arterial pressure.

* International Biophysics Corporation, Irvine, Calif, USA

** Nihon Koden, Tokyo, Japan 
The drug study was performed in 2 groups of animals ; 3 dogs without myocardial ischemia (non-ischemic group) and 22 dogs with myocardial ischemia (ischemic group). The myocardial ischemia was produced by occlusion of the second or third diagonal branch with a silk encircled around the vessels. Myocardial $\mathrm{pO}_{2}$ decreased promptly after the occlusion and usually leveled off within $10 \mathrm{~min}$ as shown in Fig. 1. In several animals, however, the myocardial $\mathrm{pO}_{2}$ once reduced was gradually returned to the control value before occlusion, as depicted in Fig. 2. In those animals, additional occlusion was applied to the adjacent small branches which seemed to be contributory to the perfusion to the particular area.

When stable state was obtained, in animals of either group, allopurinol dissolved as reported by Kann and his associates ${ }^{12)}$ was administered in the dose of $50 \mathrm{mg}$ per $\mathrm{Kg}$ body weight. The drug was continuously infused in the femoral vein during a $10 \mathrm{~min}$ period. Following observation for about $20 \mathrm{~min}$, the snare around the coronary artery was released in animals of ischemic group.

At the end of the study, the electrodes were calibrated at $37^{\circ} \mathrm{C}$ against lactated Ringer solution which had been saturated with air by insufflation.

\section{Results}

The myocardial $\mathrm{pO}_{2}$ prior to coronary artery occlusion was $28 \pm 10$ mmHg. Due to the considerable variation of the value, the change of myocardial $\mathrm{pO}_{2}$ was expressed in percentage of the control value before occulsion.

Ligation of the coronary artery did not cause any significant change either in heart rate or in blood pressure. Following administration of allopurinol,
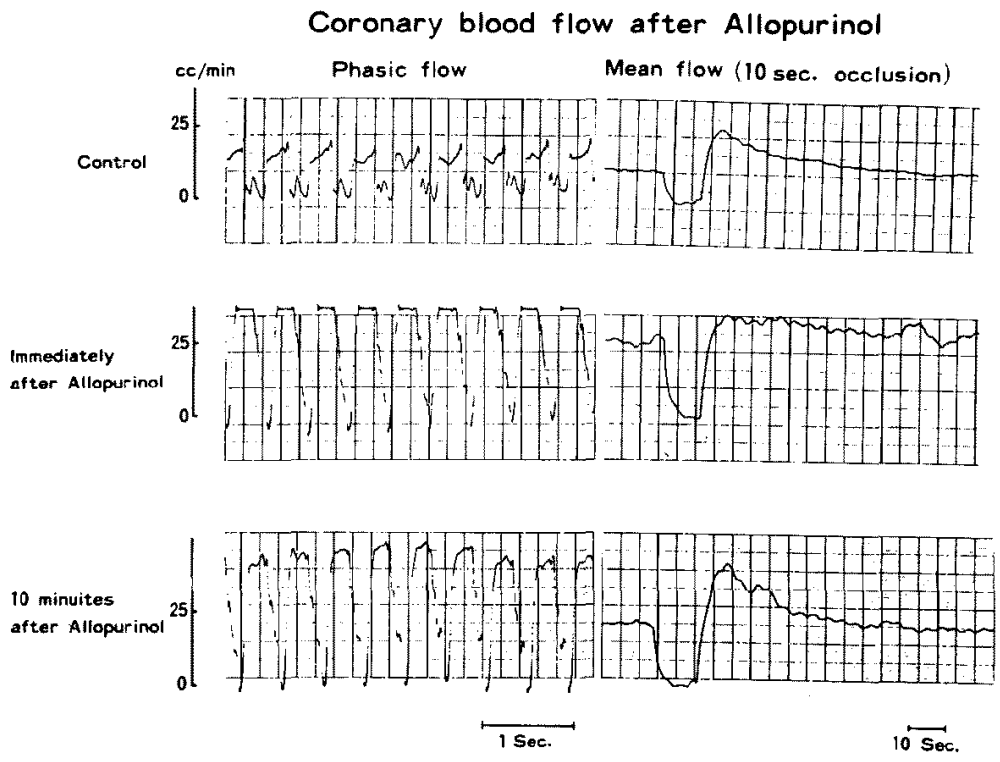

Fig. 3. Blood flow in the unobstructed circumflex branch of the left coronary artery before and after administration of allopurinol. 

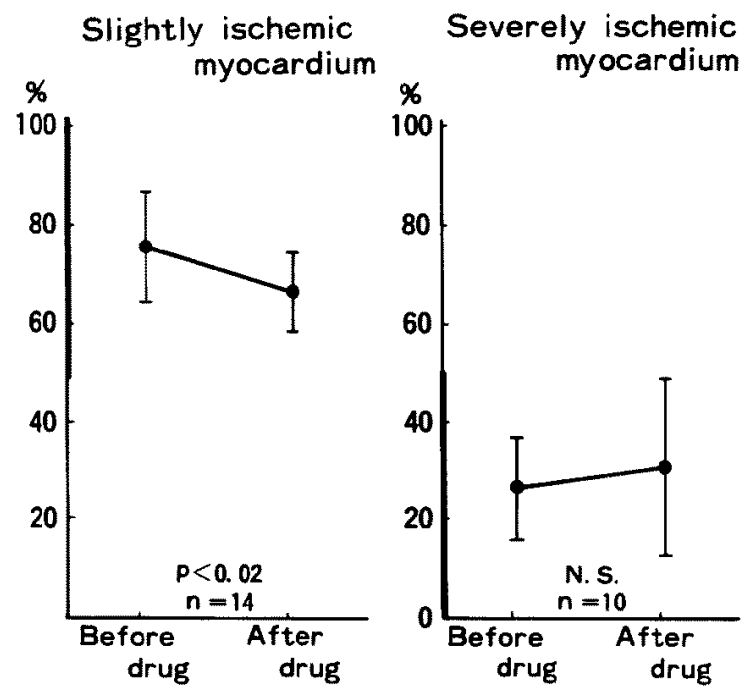

Fig. 4. Change of $\mathrm{pO}_{2}$ in the slightly ischemic (left graph) and severely ischemic myocardium (right graph) before and after administration of allopurinol.

Average values and standard errors were shown. Statistical analysis was done by paired Student's test.

Table I. Changes of Myocardial $\mathrm{pO}_{2}$ after Allopurinol Infusion

\begin{tabular}{|c|c|c|c|c|c|}
\hline \multicolumn{3}{|c|}{ Slightly Ischemic Myocardium } & \multicolumn{3}{|c|}{ Severely Ischemic Myocardium } \\
\hline Exp.\# & Before drug & After drug & Exp.\# & Before drug & After drug \\
\hline 2 & $70 \%$ & $60 \%$ & 7 & $20 \%$ & $18 \%$ \\
\hline 3 & 74 & 58 & 8 & 19 & 21 \\
\hline 4 & 88 & 75 & 9 & 42 & 63 \\
\hline 5 & 83 & 81 & 10 & 26 & 29 \\
\hline 6 & 78 & 75 & 12 & 41 & 45 \\
\hline 7 & 67 & 73 & 16 & 39 & 39 \\
\hline 10 & 63 & 58 & 19 & 30 & 54 \\
\hline 11 & 80 & 68 & 20 & 21 & 16 \\
\hline 13 & 67 & 67 & 21 & 14 & 14 \\
\hline 14 & 59 & 67 & 22 & 13 & 14 \\
\hline 15 & 92 & 67 & \multirow{4}{*}{ Mean } & \multirow{2}{*}{$27 \%$} & \multirow{2}{*}{$31 \%$} \\
\hline 17 & 88 & 76 & & & \\
\hline 18 & 62 & 57 & & \multicolumn{2}{|c|}{ (N. S.) } \\
\hline 18 & 84 & 58 & & & \\
\hline \multirow{2}{*}{ Mean } & $75 \%$ & $67 \%$ & & & \\
\hline & \multicolumn{2}{|c|}{$(\mathrm{p}<0.02)$} & & & \\
\hline
\end{tabular}


heart rate increased from $137 \pm 20$ to $164 \pm 20$ beats per $\min (\mathrm{p}<0.01)$. Mean systemic arterial pressure decreased from $130 \pm 21$ to $115 \pm 19 \mathrm{mmHg}(\mathrm{p}<$ 0.01). Blood flow in the circumflex branch of the left coronary artery increased more than twice as much as the control, as shown in Fig. 3.

In the non-ischemic group of animals administration of allopurinol did not cause any significant changes in the myocardial $\mathrm{pO}_{2}$. In the ischemic group, changes of myocardial $\mathrm{pO}_{2}$ following the drug injection differed considerably according to the degree of ischemia produced as shown in Fig. 4 and Table I. In the slightly ischemic myocardium, where $\mathrm{pO}_{2}$ was reduced more than $50 \%$ of the control by ligation of the coronary artery, administration of allopurinol brought about a further decrease in myocardial $\mathrm{pO}_{2}$. The myocardial $\mathrm{pO}_{2}$ decreased from $75 \pm 11$ to $67 \pm 8 \%$ of the control $(\mathrm{p}<0.02)$ following the drug infusion. Figs. 1 and 2 show typical tracings of myocardial $\mathrm{pO}_{2}$ in the slightly ischemic myocardium.

In the severely ischemic myocardium, where the myocardial $\mathrm{pO}_{2}$ was reduced more than $50 \%$ of the control by coronary occlusion, the myocardial $\mathrm{pO}_{2}$ increased from $27 \pm 10$ to $31 \pm 17 \%$ of the control following the infusion. The change, however, was not significant statistically.

\section{Discussion}

Theoretically, myocardial tissue $\mathrm{pO}_{2}$ value represents the net balance between myocardial oxygen supply and consumption. ${ }^{8), 9)}$ Occlusion of the coronary artery promptly reduces the tissue $\mathrm{pO}_{2}$ of the myocardium supplied by the vessel indicating myocardial hypoxia. Occasionally, myocardial $\mathrm{pO}_{2}$ once reduced recovers to some extent, probably because collateral channels open up rapidly in the face of acute myocardial hypoxia. It is probable that contraction of the myocardium previously supplied by the vessel occluded diminished due to myocardial hypoxia, resulting in a decrease in oxygen consumption of that particular arca. The observation that this recovery does not always take place favors the former explanation.

Allopurinol significantly increased the blood flow in the unobstructed coronary artery. The fact that no significant changes occurred in $\mathrm{pO}_{2}$ of the myocardium supplied by the unobstructed vessel indicates that the increase in blood flow was counterbalanced by the increase in oxygen consumption of the myocardium following infusion of allopurinol.

In the slightly ischemic myocardium, administration of allopurinol produced a further diminution in myocardial $\mathrm{pO}_{2}$. Since the blood flow and oxygen consumption of the ischemic myocardium were not measured separately, it is not possible to deduce the precise mechanism by which the ag- 
gravation of myocardial hypoxia was induced by allopurinol. However, it is not unreasonable to assume that this is due to the decrease in perfusion pressure and/or increased oxygen demand. This may well be interpreted as an example of coronary steal phenomenon as has been observed in the periinfarction zone, when isoproterenol is administered in myocardial infarction. ${ }^{13)}$

In the severely ischemic myocardium, myocardial $\mathrm{pO}_{2}$ increased slightly following allopurinol administration. The change was not significant by Student's test. In 8 out of 10 studies of severely ischemic myocardium, changes of myocardial $\mathrm{pO}_{2}$ were less than $10 \%$ of the control value. Therefore, it is reasonable to state that myocardial $\mathrm{pO}_{2}$ in the center of infarction was not altered by drug administration. It is quite possible that amount of drug which reached the center of infarction was not sufficient to open up the scanty collateral vessels around the area.

When the coronary arterial blood supply suddenly ceases, the myocardium in its distribution becomes severely hypoxic; energy producing mechanism is shifted to glycolysis. Production of ATP is markedly diminished. Braasch and his associates reported that tissue ATP content fell remarkably after occlusion of the coronary artery in dogs. ${ }^{14}$ ) It was also reported that inorganic phosphorus was released from the ischemic myocardium, indicating the breakdown of high energy phosphate compound. ${ }^{15}$ Crowell and associates suggested that an irreversible arrest of energy consumption results from the degradation of the high energy phosphates. ${ }^{2)}$ Catabolism of these compounds produces the intermediate adenosine and other related compounds which diffuse out of the cell ultimately to be converted to uric acid by the enzyme xanthine oxidase. The cell possesses resynthesis pathways so that hypoxanthine and higher compound can be converted to ATP; therefore these compounds are termed functional purine bases. With the conversion of hypoxanthine to xanthine and conversion of the latter to uric acid by xanthine oxidase, the functional purine bases become irreversibly lost, since the conversion of xanthine to uric acid is irreversible.

DeWall and associates reported that allopurinol caused an increase in cardiac performance, reversed or prevented electrocardiographic ST-T changes and exhibited prolonged antiarrhythmic effects in animals with acute myocardial infarction. ${ }^{6}$ ) They postulated that the key to metabolic support of the acutely ischemic myocardium is the maintenance of the total body pool of the functional purine bases by blocking the action of xanthine oxidase, thus these substrates would be available for reformation of ATP permitting recovery of the damaged muscle. They also observed pinking of the ischemic myocardium following the use of allopurinol and pointed out the possibility 
of the chemical revascularization of the myocardium; the opening of previously nonfunctioning intramural channels or collaterals or prevention of vasospasm. This is a pausible theory since adenosine, a potent dilator of coronary vessels and possible mediator of coronary blood flow regulation, ${ }^{16}$ ) will be accumulated in the hypoxic area due to prevention of breakdown of adenosine to uric acid by allopurinol.

The present study was undertaken to investigate whether or not the chemical revascularization takes place with allopurinol. Results of the current study did not substantiate the possibility at least in the slightly ischemic myocardium which may well simulate the periinfarction area. If the collaterals open up, myocardial $\mathrm{pO}_{2}$ should increase after the use of the drug. Contrary to our expectations, myocardial $\mathrm{pO}_{2}$ was found to decrease upon the use of the drug in the current study. As far as oxygen metabolism is concerned allopurinol is apparently detrimental, since the agent aggravates myocardial hypoxia in the ischemic periinfarction zone.

However, it has to be noted that the apparent negative oxygen balance in the slightly ischemic myocardium could be counterbalanced by the protective effects of the agent on the hypoxic myocardium through preserving functional purine bases. Therefore, it is not possible to draw a final conclusion from the current study as to whether allopurinol is beneficial or detrimental in patients with acute myocardial infarction. Additional metabolic studies are indicated to elucidate the net effect of the agent on the ischemic myocardium. In the severely ischemic myocardium where the negative oxygen balance was not brought about by administration of the agent, theoretical protective mechanism of the agent could have a more favorable effect than in the slightly ischemic myocardium.

\section{REFERENCES}

1. Elion GB, Kovensky A, Hitchings GH: Metabolic studies of allopurinol, an inhibitor of xanthine oxidase. Biochem Pharmacol 15: 868, 1966

2. Crowell JW, Jones CE, Smith EE: Effect of allopurinol on hemorrhagic shock. Am J Physiol 216: 744,1969

3. Brueckner UB, Opherk D, Schmier J, Treumer H, Schwarz G: Kreislaufdynamik und Kontraktilitaet des Herzens im Tourniquetschock des Hundes bei Hemmung der Blutgerinnung und der Xanthinoxydase. Z Kreislaufforsch 61: 161, 1972

4. Parker JC, Smith EE: Effects of xanthine oxidase inhibitor in cardiac arrest. Surgery $\mathbf{7 1}$ : 339,1972

5. Toledo-pereyra LH, Najarian JS: Total recovery of ischemic kidneys treated with allopurinol before transplantation. Surg Forum 24: 302, 1973

6. DeWall RA, Vasko KA, Stanley EL, Kezdi P: Response of ischemic myocardium to allopurinol. Am Heart J 82: 362, 1971

7. Granson J, Irvine M, Parrat JR, Cunningham J: Vasospastic elements in myocardial infarc- 
tion following coronary occlusion in the dog. Cardiovasc Res 2: 54, 1968

8. Rakusun K: Oxygen in the Heart Muscle. Charles C Thomas Publisher, Springfield, Ill, 1971

9. Brantigan JW, Perna AM, Gardner TJ, Gott VL: Intramyocardial $\mathrm{PO}_{2}$ and $\mathrm{PCO}_{2}$ in the canine heart during anoxic cardiac arrest. Surg Gynecol Obst 143: 67, 1972

10. Furuse A, Brawley RK, Gott VL: Effects of isoproterenol, 1-norepinephrine, and glucagon on myocardial gas tensions in animals with coronary artery stenosis. J Thorac Cardiovasc Surg 65: 815,1973

11. Harris, TR, Nugent $\mathbf{M}$ : Continuous arterial oxygen tension monitoring in the newborn infant. J Pediat 82: 929, 1973

12. Kann HE, Jr, Wells JH, Gallelli JF, Shein PS, Cooney DA, Smith ER, Seegmiller JE, Carbone PP: The development and use of an intravenous preparation of allopurinol. Am J Med Sci 256: 53,1968

13. Sharma GVRK, Kumar R, Molokhia F, Messer JV: Coronary steal. Regional myocardial blood flow studies during myocardial infarction. Clin Res 19; 338, 1971

14. Braasch W, Gudbjarnason S, Puri PS, Ravans KG, Bing RF : Early changes in energy metabolism in the myocardium following acute coronary occlusion in anesthetized dogs. Circulat Res 23: 429, 1969

15. Owen P, Thomas M, Young V, Opie L: Comparison between metabolic changes in local venous and coronary sinus blood after acute coronary occlusion. Am J Cardiol 25: 562, 1970

16. Berne RM: Cardiac nucleotide in hypoxia. Possible role in regulation of coronary blood flow. Am J Physiol 204: 317, 1963 